\title{
Comportamento Estrutural de Alvenarias Construídas com Blocos de Terra Compactados (BTC)
}

\author{
Givanildo Alves de Azeredo \\ Geilson Marques de Oliveira \\ José Diego Formiga Dantas \\ Francisco Eli Freire dos Santos \\ Aline Figueiredo Nóbrega de Azeredo \\ Gibson Rocha Meira
}

\section{Introdução}

A terra é provavelmente um dos materiais mais antigos usados na construção de edificaçôes residenciais. Em várias partes do Brasil, pode-se encontrar inúmeras edificações cujo sistema construtivo teve a terra como seu principal material de construção. Geralmente, nessas construçóes, a terra era usada na fabricação de blocos, os quais, por sua vez, eram usados na construção de alvenarias. Segundo Heathcote (1995), as construçóes de terra antigas são patrimônios culturais e de valor artístico muito importante.

As edificações em terra podem ser construídas segundo diversos sistemas construtivos, quais sejam: paredes monolíticas, também conhecidas como taipa de pilão, alvenarias ou taipa. As paredes monolíticas costumam ter espessura bem superior às de alvenaria que, por sua vez, são construídas com adobes.

O adobe é um bloco de terra moldado e compactado à mão. Ele tanto pode ser queimado como pode ser utilizado cru. Dependendo das propriedades requeridas, pode-se escolher um ou outro tipo de fabricação. Fabricados com terra bastante argilosa, com teor de no mínimo $25 \%$ de argila, os adobes geralmente são estabilizados com cal ou com cimento, a depender da natureza da argila que constitui a terra. A estabilização oferecida pela cal ou 
pelo cimento tem o objetivo de oferecer aos produtos fabricados com terra a resistência apropriada à água. Vale salientar que tanto a cal quanto o cimento, nesse caso, não exerce a função de ligante, pois a argila presente na terra já possui essa propriedade.

O teor de estabilizante dependerá da natureza e do teor da argila que constitui a terra. Um tijolo de adobe fabricado com uma argila do grupo esmectita exigirá quantidade muito maior de estabilizante se comparado a um tijolo fabricado com uma argila caulinítica, por exemplo. A montmorilonita, pertencente ao grupo da esmectita, possui al to poder expansivo. Em contato com a água, a adsorção por parte da argila influenciará na estabilidade dimensional do adobe. Sem a presença de um estabilizante, um adobe fabricado com uma argila montmorilonítica pode fissurar-se durante o processo de secagem. Isso acontece porque a montmorilonita adsorve água tanto na superfície externa como na superfície interna dos folhelhos, provocando o fenômeno da expansão. A caulinita, por sua vez, adsorve apenas na superfície externa dos folhelhos. Observa-se, então, a grande importância em se conhecer a terra que será utilizada nas construções.

$\mathrm{Na}$ fabricação de blocos, a escolha do cimento como estabilizante se dá principalmente devido ao fato de ele apresentar uma pega rápida, sobretudo nos momentos iniciais de manuseio dos adobes, que compreendem a desmoldagem, a secagem e a estocagem. Mesmo quando o estabilizante escolhido é a cal, aconselha-se o uso de percentuais mínimos de cimento, no intuito de facilitar a manipulação dos produtos fabricados. $\mathrm{Na}$ execuçáo de alvenarias, entretanto, o ideal é sempre se utilizar uma argamassa com presença de cimento, com o propósito de náo atrasar a produtividade. $\mathrm{O}$ emprego apenas de cal, cuja pega é demorada, poderia certamente provocar desalinhamentos ou desaprumos indesejados à alvenaria. $\mathrm{O}$ mesmo se pode dizer para a execução de fundações. Caso não se tenha cimento, sugerese, então, o uso de algum material pozolânico de alta reatividade que, ao reagir com a cal, produzirá também, como resultado da reação, um material cimentício.

Guettala et al. (2006) indicaram que pelo menos $50 \%$ da população do mundo ainda vive em casas de terra. No entanto, a principal desvantagem da terra como um material de construção é a sua deterioração sob a ação das intempéries. Essa deterioração muitas vezes resulta em falha estrutural, daí a necessidade de estabilização. 
Segundo Prompt e Borella (2010), a construção com terra teve seu uso largamente difundido no Brasil durante o período colonial. Em 1535, a igreja mais antiga do Brasil, dos Santos Cosme e Damiāo, foi erguida originalmente em taipa, na região metropolitana de Recife (SANTOS, 2015). A terra era usada na fabricação de adobes ou na construção de edificaçóes de taipa. Os adobes eram queimados, na maioria das vezes, em fornos construídos artesanalmente pelo interior do país, os quais utilizavam madeira como combustível. No caso, eles se transformavam em tijolos cerâmicos maciços e adquiriam capacidade portante. No caso da taipa, a função estrutural é exercida pela madeira, sendo a terra utilizada para vedar os espaços vazios da estrutura.

Os blocos de terra compactada, também conhecidos como blocos de terra comprimida (BTC), são descendentes do adobe. Diferem-se, entretanto, pelo modo de fabricação: os adobes são moldados à mão, já os BTC são moldados em prensas mecânicas ou hidráulicas. A inovação tecnológica teve o intuito de aprimorar as antigas técnicas de construção em terra, notadamente o adobe seco ao sol. A prensa mecânica consegue produzir blocos densos, de forma regular e com maior resistência à água do que os simples adobes.

Desse modo, o surgimento dos BTC veio unir o tradicional ao moderno. Observa-se que essa nova técnica, ou seja, o uso de prensas mecânicohidráulicas com energia de prensagem importante, surgiu com o avanço da tecnologia e da engenharia. Porém, o material usado é antigo, o que remete às construçóes coloniais tradicionais.

O tijolo de solo-cimento, em forma de adobe ou de BTC, constitui uma das alternativas para a construção de alvenaria. Esse elemento, após pequeno período de cura, garante resistência à compressão simples similar à dos tijolos cerâmicos, sendo a resistência tanto mais elevada quanto maior for a quantidade de cimento empregada.

Este capítulo apresenta conceitos e particularidades da terra como material de construção e, principalmente, resultados sobre o comportamento mecânico-estrutural de alvenarias de terra, constituídas de BTC.

\section{Generalidades Sobre Estruturas de Terra}

A avaliação do comportamento estrutural de sistemas construídos com BTC envolve o estudo sobre o processo de fabricação dos blocos de terra compactada (BTC) e, em seguida, a compreensão de como as cargas agem 
nesse tipo de estrutura, no caso a alvenaria. O fato dos BTC apresentarem módulo de elasticidade mais baixo que os blocos cerâmicos e os de concreto faz com que, para uma dada tensão, as alvenarias de BTC se deformem mais.

O bloco com terra compactada (BTC) é uma forma moderna da aplicação da terra como material de construção. $\mathrm{Na}$ década de 50 , foi concebida pelo pesquisador colombiano G. Ramires a primeira prensa manual, denominada de CINVA-RAM (BROWN et al., 2014). Em seguida, surgiu a prensa Mattone e também várias outras prensas hidráulicas, como a brasileira Ecobrava, com energia de prensagem maior, além de menor esforço físico gasto na produção dos blocos.

Segundo Gonçalves (2005), faz-se necessária a construção das curvas granulométricas do solo. Por exemplo, a plasticidade do solo deve ser verificada por meio dos ensaios de Atterberg. O limite de liquidez deve se enquadrar de preferência no intervalo 40-45\%. De acordo com Barbosa e Ghavami (2007), quanto ao tipo de solo, admite-se que as proporçôes adequadas dos componentes do solo são: 10 a 20\% de argila; 10 a 20\% de silte e 50 a $70 \%$ de areia. Para Pinto (1980), o solo ideal deve conter 15\% de silte mais argila, $20 \%$ de areia fina, 30\% de areia grossa e 35\% de pedregulho, sendo mais indicados os solos arenosos bem graduados e com razoável quantidade de silte mais argila, uma vez que exigem baixo consumo de cimento. Já a Portland Cement Association (PCA, 1969) considera excelentes os solos arenosos e pedregulhosos, contendo de 65 a $90 \%$ de areia e quantidade de silte mais argila variando de 10 a $35 \%$.

\section{Comportamento Mecânico das Alvenarias}

De acordo com Page (1978), geralmente o sistema construtivo de alvenaria era analisado considerando uma associação de blocos e juntas de argamassa.O material desse sistema tinha suas propriedades reológicas baseadas em uma média das propriedades dos blocos e da argamassa. Esse material equivalente tinha seu modelo constitutivo considerado como elástico e isotrópico. Além disso, como o sistema era considerado contínuo, não havia, portanto, interfaces entre blocos e juntas de argamassas, tornando-se impossível avaliar modos de ruptura tipo I e II, devido à tração e cisalhamento, respectivamente. Page (1978) foi um dos primeiros pesquisadores a considerar a alvenaria como uma estrutura constituída de dois materiais, o material do bloco e o material da argamassa. $\mathrm{O}$ primeiro tinha comportamento elástico e o outro, inelástico. 
As características de ruptura na junta, definida pela violação do critério de resistência de aderência à tração ou ao cisalhamento, foram implementadas em um programa baseado no Método dos Elementos Finitos, sendo modeladas as propriedades não lineares da junta e permitida a ocorrência de ruptura progressiva dessa junta (PAGE, 1978).

Segundo Tauil e Martins Nese (2010), as alvenarias são constituídas por elementos que estâo unidos uns aos outros por meio de juntas de argamassa. O conjunto deve formar um elemento coeso e resistente, capaz de suportar esforços horizontais e verticais. Esse tipo de sistema construtivo tanto pode ter função estrutural como apenas de vedação.

De acordo com Roman et al. (2007), além de resistir às cargas advindas do próprio peso e das sobrecargas provocadas pelo carregamento da estrutura, as alvenarias também devem suportar esforços laterais, provocados tanto pela açáo do vento como pelo desaprumo das alvenarias.

Em estudo com alvenarias de terra comprimida, Gonçalves (2005) aplicou carregamentos em ciclos nas alvenarias, para verificar o comportamento dos muros também no descarregamento. Extensômetros mecânicos foram instrumentados para a obtençáo dos deslocamentos. A carga de ruptura máxima foi da ordem de $250 \mathrm{kN}$. Gonçalves (2005) ainda fez esse estudo em alvenarias com abertura (portas e janelas), usando vergas e contravergas, e estudos em alvenarias sem abertura. As mesmas foram feitas com três alturas diferentes: 2,60 m; 1,80 m e 1,0 m. Ele observou que, em geral, as alvenarias ficam sujeitas a uma flexo-compressão oblíqua. Consequentemente, não se consegue um modo único de ruptura.

\section{Interações Entre Alvenarias}

A NBR - 15961 não especifica interaçôes entre alvenarias, porém determina que cargas de compressão localizadas sobre apenas uma parte do comprimento de uma alvenaria tendem a se espalhar ao longo da altura da alvenaria, segundo um ângulo de $45^{\circ}$ (Figura 1). Na Figura 2, observa-se claramente o efeito das tensóes de cisalhamento ao longo da aresta que une os dois planos.

Segundo (VENDRAME, 2008), a interação entre as alvenarias proporciona melhor distribuição das ações verticais em um pavimento, possibilitando assim uma redução na resistência das unidades a serem utilizadas. 
No caso de alvenarias com aberturas, também podemos visualizar linhas de tensôes de cisalhamento que dividem um único plano em partes, como apresentado na Figura 3. Segundo Vendrame (2008), uma alvenaria com aberturas é considerada geralmente como uma série de alvenarias independentes. Tais alvenarias são unidas através de tensóes internas, normais no plano XY, e de cisalhamento. Como vantagem, os carregamentos ficam mais uniformizados. A NBR-15961 também prevê para esses casos um espalhamento segundo um ângulo de $45^{\circ}$, que é interrompido nas aberturas, excluindo as zonas limitadas por planos inclinados a $45^{\circ}$ (Figura 4 ).
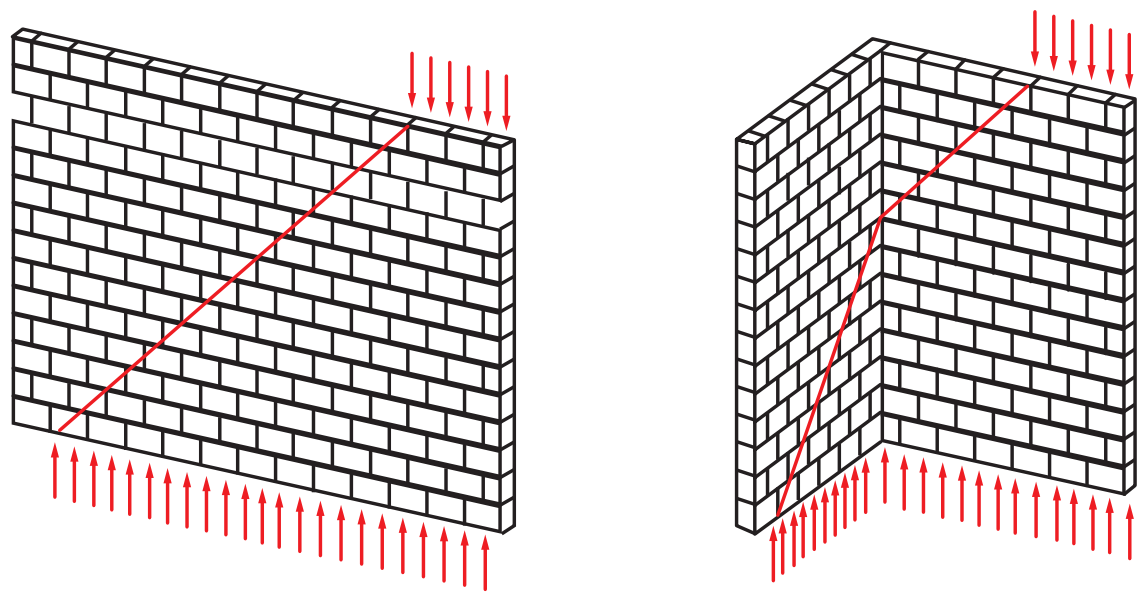

Figura 1. Espalhamento de carregamento em alvenarias planas e em L. Fonte: Ramalho e Corrêa (2003).
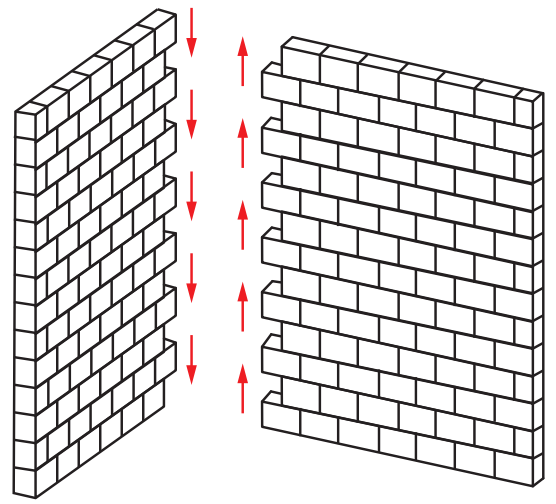

Figura 2. Interação entre cantos de alvenarias. Fonte: Ramalho e Corrêa (2003). 

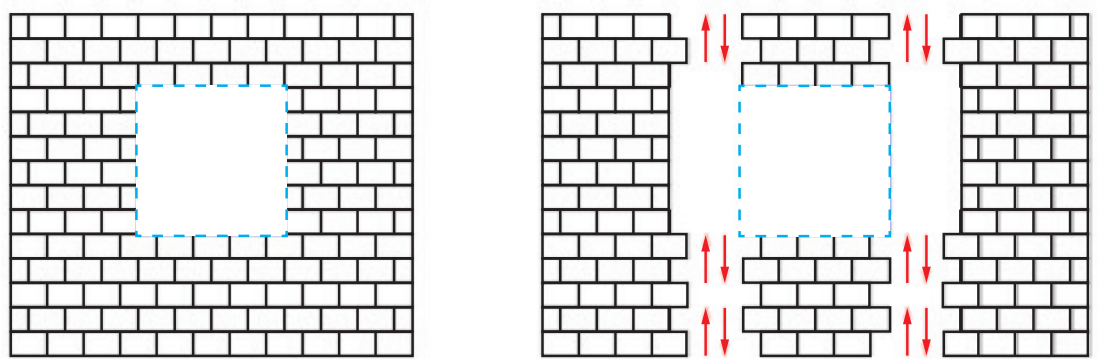

Figura 3. Interação de alvenarias em região de janelas. Fonte: Ramalho e Corrêa (2003).
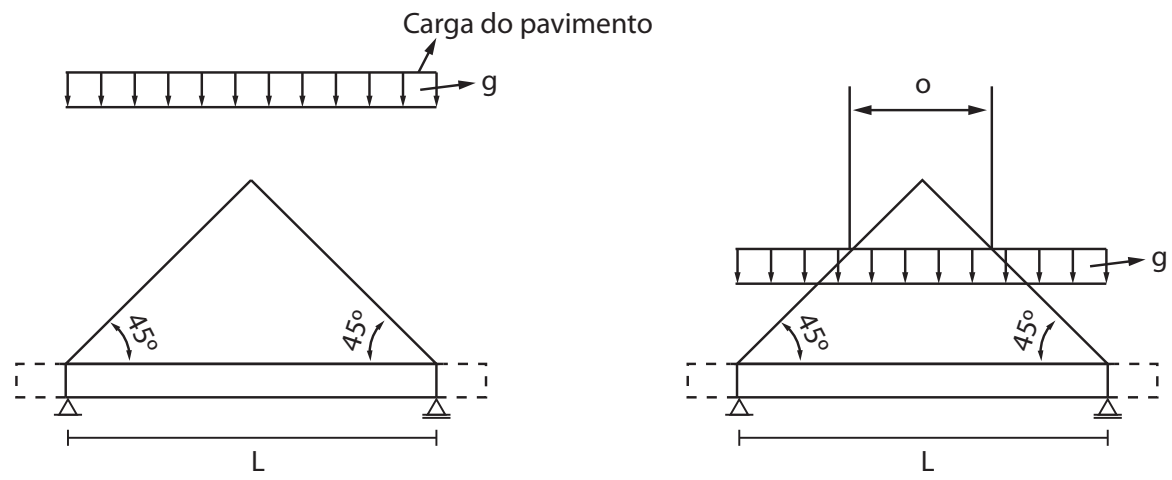

Figura 4. Distribuição das ações tipo carregamento distribuído acima da verga em alvenarias com abertura segundo a NBR - 15961. Fonte: Ramalho e Corrêa (2003)

\section{Tipos de Carregamentos e Ruptura}

Atualmente, os ensaios de resistência à compressão simples em paredes e alvenarias são realizados por meio de aplicação de carregamento uniformemente distribuído. Entretanto, na prática, tais elementos estruturais estão submetidos a carregamentos distribuídos de maneira não uniforme. A propriedade primordial na análise do comportamento mecânico da alvenaria é a sua capacidade resistente à açáo de esforços de compressão normais ao seu plano vertical (, 1993). Existem outras propriedades, no entanto, que também são importantes para se verificar o comportamento estrutural da alvenaria: a resistência aos esforços de flexão, a resistência ao cisalhamento e a resistência à tração (MEDEIROS, 1993). Esses esforços, porém, não entram no escopo investigativo do presente capítulo. 
Devido à ação de cargas uniformemente distribuídas, as fissuras aparecem em trechos contínuos e verticais. A Figura 5 apresenta um estado de fissuração originado pela deformação transversal da argamassa de assentamento e da eventual fissuraçáo de blocos ou tijolos por flexáo local (BAUER, 2007).

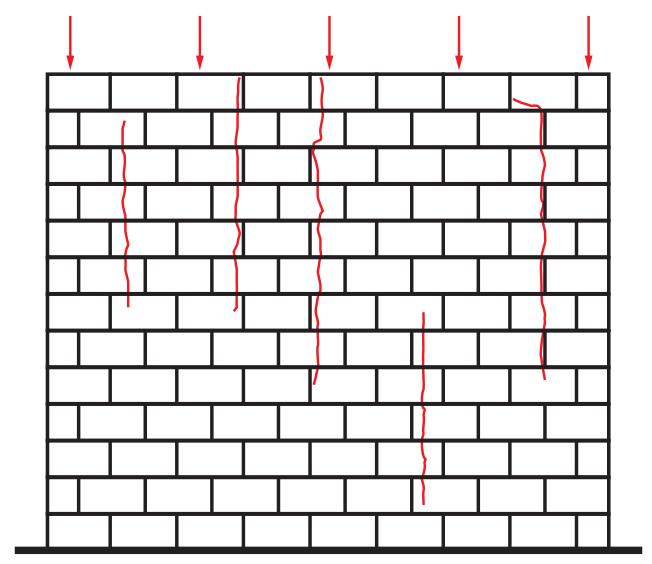

Figura 5. Configuração das fissuras originadas pelo carregamento excessivo de compressão. Fonte: Baver (2007).

Sampaio (2010) descreve que os peitoris de janela são regiōes onde comumente há concentração de tensões. Informa também que, nessas regióes, devido à sobrecarga, poderá haver a ocorrência de fissuras, que se manifestarão de forma vertical, conforme ilustrado na Figura 6.

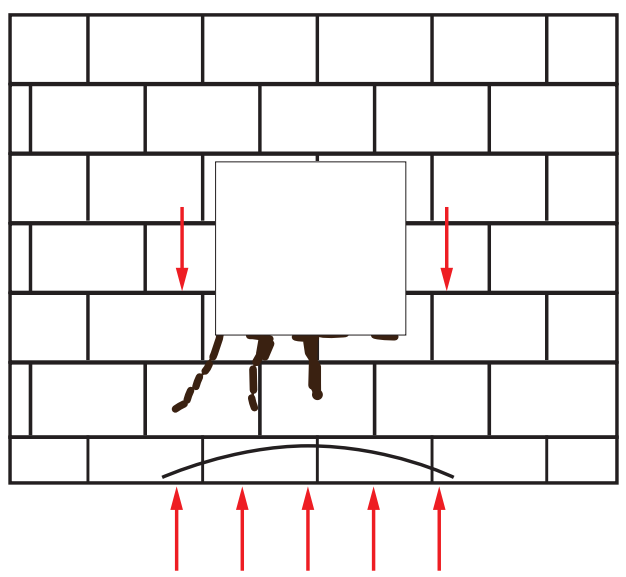

Figura 6. Concentração de tensões sob abertura. Fonte: Sampaio (2010). 


\section{Programa Experimental}

O programa experimental aqui desenvolvido refere-se a ensaios de ruptura de dois tipos de alvenaria, uma em L, de $1 \mathrm{~m}$ de altura, conforme mostrado na Figura 7, e outra com abertura de $2,15 \mathrm{~m}$ de altura, como mostrado na Figura 8. A alvenaria em L foi concebida no intuito de simular alvenarias que recebessem cargas de lajes pré-moldadas armadas em uma (01) direção. A carga foi aplicada em somente um dos lados da alvenaria, no intuito de se verificar, experimentalmente, o efeito da transferência de esforços de um lado para o outro. Como ilustra a Figura 7, no lado carregado da alvenaria, foi utilizado um perfil metálico de modo a aplicar o carregamento de forma distribuída. A célula de carga utilizada tem a capacidade de $1000 \mathrm{kN}$. Três defletômetros foram utilizados para medir o encurtamento de cada alvenaria. Um defletômetro foi usado para medir o deslocamento lateral. Todavia, esse efeito de deslocamento fora do plano de carregamento não será abordado por este capítulo. Na alvenaria em L, todos os defletômetros foram posicionados em um quadrado central delimitado pelos terços centrais da altura e comprimento da alvenaria. Os defletômetros D1 e D2 encontram-se situados à mesma altura, porém o D2 está mais próximo da amarração entre as alvenarias.

$\mathrm{Na}$ alvenaria com abertura, os defletômetros foram posicionados da seguinte forma: um na parte lateral da abertura à sua meia altura (D1), um na regiáo central abaixo da contraverga (D2) e um na região central acima da verga (D3). Os sinais de carga e deslocamento foram coletados por intermédio de um "data logger", modelo 2890-9 da Almemo. Outros dados dos ensaios experimentais serão descritos juntamente com a análise dos resultados.

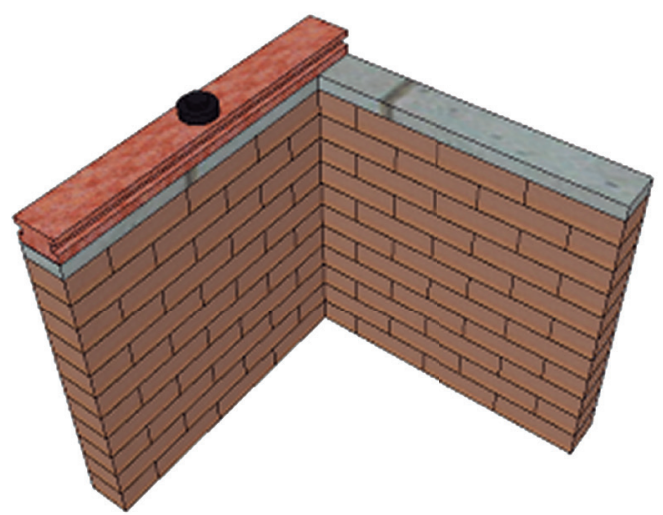

Figura 7. Alvenaria em L. Fonte: Própria. 


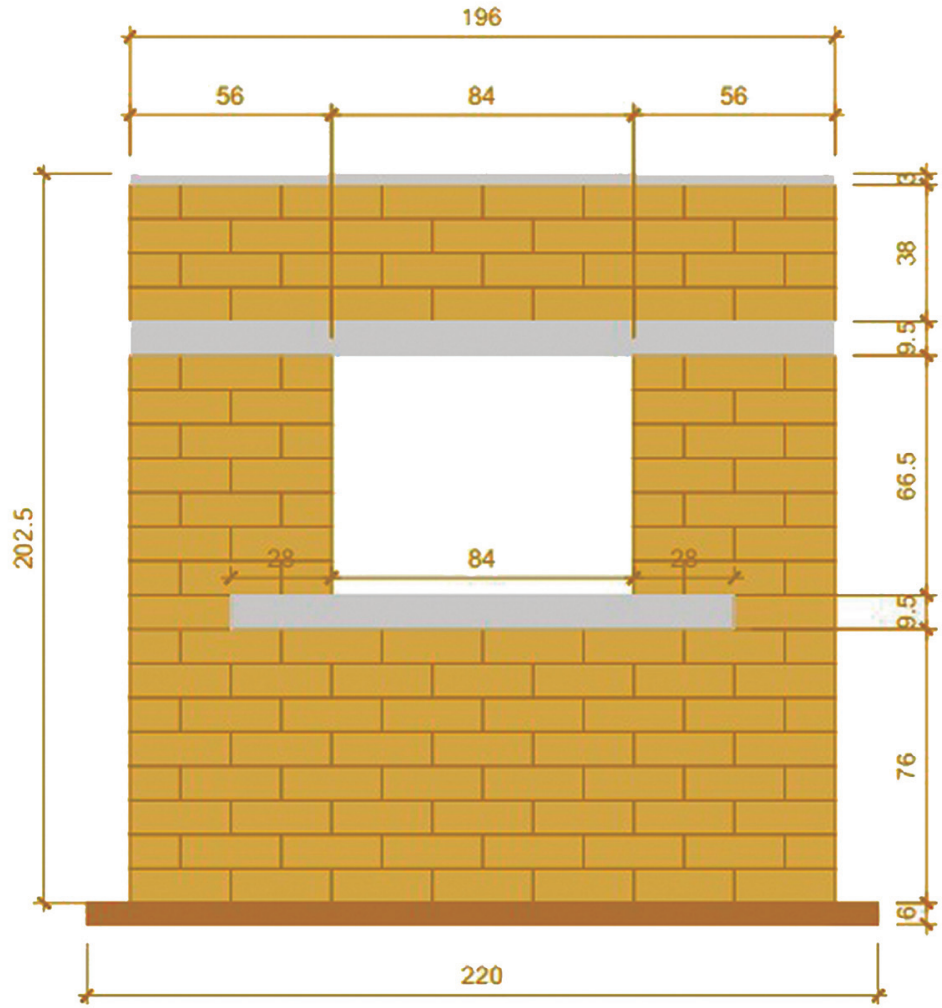

Figura 8. Alvenaria com abertura. Fonte: Própria.

\section{Caracterização da Terra}

O solo empregado na presente pesquisa apresentou as características indicadas na Tabela 1, proporçóes que qualificam o material para a fabricação de blocos prensados.

Tabela 1. Propriedade da terra empregada.

\begin{tabular}{lllll}
\hline & Silte + argila (\%) & LP (\%) & LL (\%) & IP (\%) \\
\hline Terra & $10<20,47 \%<40$ & 20,42 & 26,36 & 5,93 \\
& & NBR 7180 (1988) & NBR 6459 (1984) & \\
\hline
\end{tabular}


O teor de areia também manteve-se dentro do intervalo indicado pela NBR NM 248 (2003): $50<\mathbf{5 0 , 9 7 \% ~ < ~ = ~ 7 0 . ~ O ~ s o l o ~ f o i ~ p e n e i r a d o ~ d e ~ m o d o ~ a ~ n a ̃ o ~}$ apresentar pedregulhos na sua composição granulométrica. A massa específica do solo foi de $2,65 \mathrm{~g} / \mathrm{cm}^{3}$, ensaio realizado de acordo com a NBR NM 52 (2009). Desse modo, o solo foi classificado como A-2-4, com no máximo $35 \%$ de (silte mais argila) passando na peneira \# 200, com LL $<40 \%$, e IP $<$ $10 \%$.

\section{Resistência à Compressão de Primas de BTC}

A NBR 10836 (ABNT 2013) determina que a resistência média dos tijolos de solo cimento deve ser igual ou superior a 2,0 $\mathrm{MPa}$ aos sete dias, mas que os valores individuais náo podem ser inferiores a 1,7 MPa. Os BTC foram estabilizados com um teor de cimento de $12 \%$. A resistência à compressão dos blocos foi medida conforme as recomendaçóes da NBR 8492 (2012), como se pode ver na Figura 9. Os blocos foram cortados e as partes foram unidas com argamassa de terra estabilizada com cimento, em uma camada fina de 2 a $3 \mathrm{~mm}$ de espessura no traço 1:12. Essa união deve garantir o nivelamento necessário à aplicação uniforme da carga. Após 48 horas de secagem, os blocos foram novamente medidos, pesados e rompidos em uma prensa hidráulica.
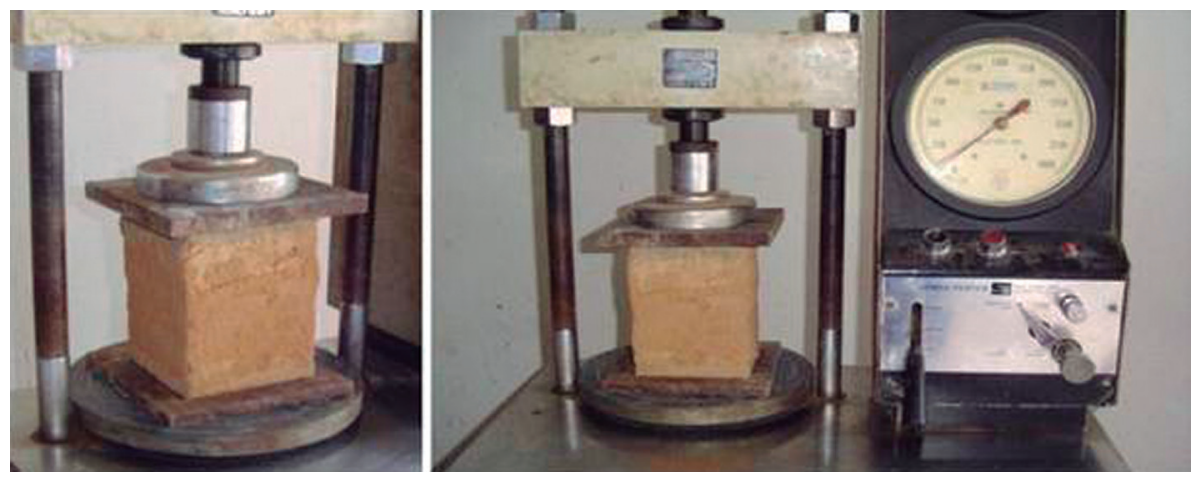

Figura 9 - Ensaio de resistência à compressão dos BTC - Fonte: Autoria própria.

A resistência à compressão simples foi obtida dividindo-se a carga de ruptura pela área da seção transversal do bloco, sem descontar a área vazada. Os resultados obtidos são apresentados na Tabela 2. 
Tabela 2. Resistência dos tijolos.

\begin{tabular}{llll}
\hline $\mathrm{CP}$ a $12 \% \mathrm{n}^{\circ}$ & Carga Ruptura (kgf) & Resistência (MPa) & Média (MPa) \\
\hline 01 & 7,752 & 3,82 & \\
\hline 02 & 7,744 & 3,81 & 3,62 \\
\hline 03 & 6,576 & 3,24 & \\
\hline
\end{tabular}

\section{Avaliação Estrutural da Alvenaria em L}

Nas Figuras 10 e 11, apresenta-se a alvenaria em L, preparada para o ensaio de ruptura. No lado carregado da alvenaria, foi utilizado um perfil metálico de modo a aplicar o carregamento de forma distribuída. No lado da alvenaria que não recebeu carregamento em seu plano, foi imposta uma condição de contorno de impedimento de deslocamento. Pode-se observar que essa condição de contorno foi simulada fisicamente por meio de duas peças de madeira. A peça inclinada encontrava-se presa ao chão através de pregos e parafusos. Dos três defletômetros usados para medir encurtamento, um foi colocado na sexta fiada (D3), a uma altura aproximada de $55 \mathrm{~cm}$ acima do piso, como mostrado na Figura 10, em um lado da parede, e dois foram colocados na oitava fiada (D1 e D2), no outro lado da parede, como mostrado na Figura 11, a uma altura de cerca de $70 \mathrm{~cm}$, acima do piso. O defletômetro D2 situa-se mais próximo da amarração que o D1.

Após ensaio de compressão, verificou-se que o rompimento se deu por esmagamento dos blocos, com efeito menor na alvenaria sem carga distribuída, como pode ser observado na Figura 12. Observa-se também uma nítida separação entre os lados das alvenarias em L, devido às tensôes de cisalhamento ali presentes, indicando transferência de tensôes de um lado para o outro, conforme apresentado na Figura 13.

$\mathrm{Na}$ Figura 14, as curvas carga-encurtamento vertical são mostradas para três defletômetros. Conforme esperado, observou-se que os defletômetros encurtaram-se na seguinte ordem: D1 > D2 > D3. No intuito de validar esse comportamento, foi realizada uma modelagem numérica contínua $3 \mathrm{D}$ do modelo proposto, com condiçóes de contorno e de carregamento $(390 \mathrm{kN})$ semelhantes ao do ensaio experimental. Os materiais argamassa e BTC foram modelados com características provenientes do ensaio experimental. 


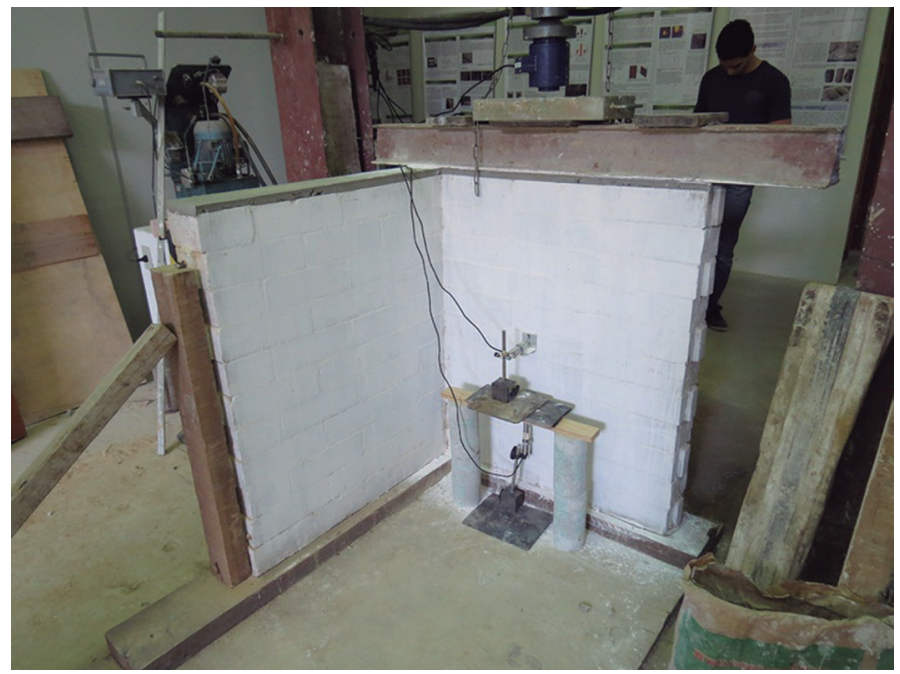

Figura 10. Instrumentação dos defletômetros, célula de carga e condição de contorno.

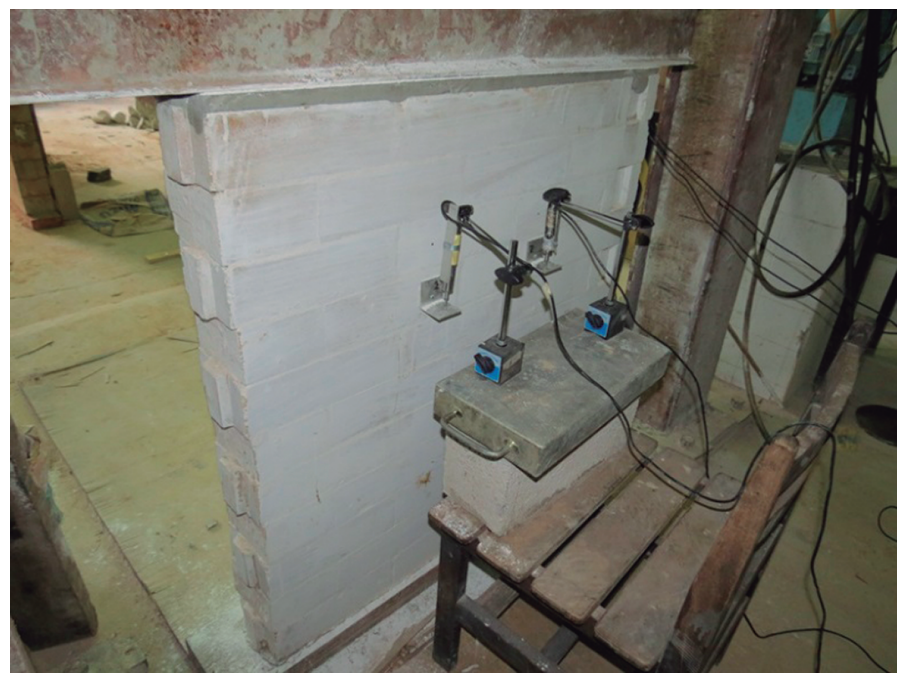

Figura 11. Instrumentação dos defletômetros - Alvenaria em L. 


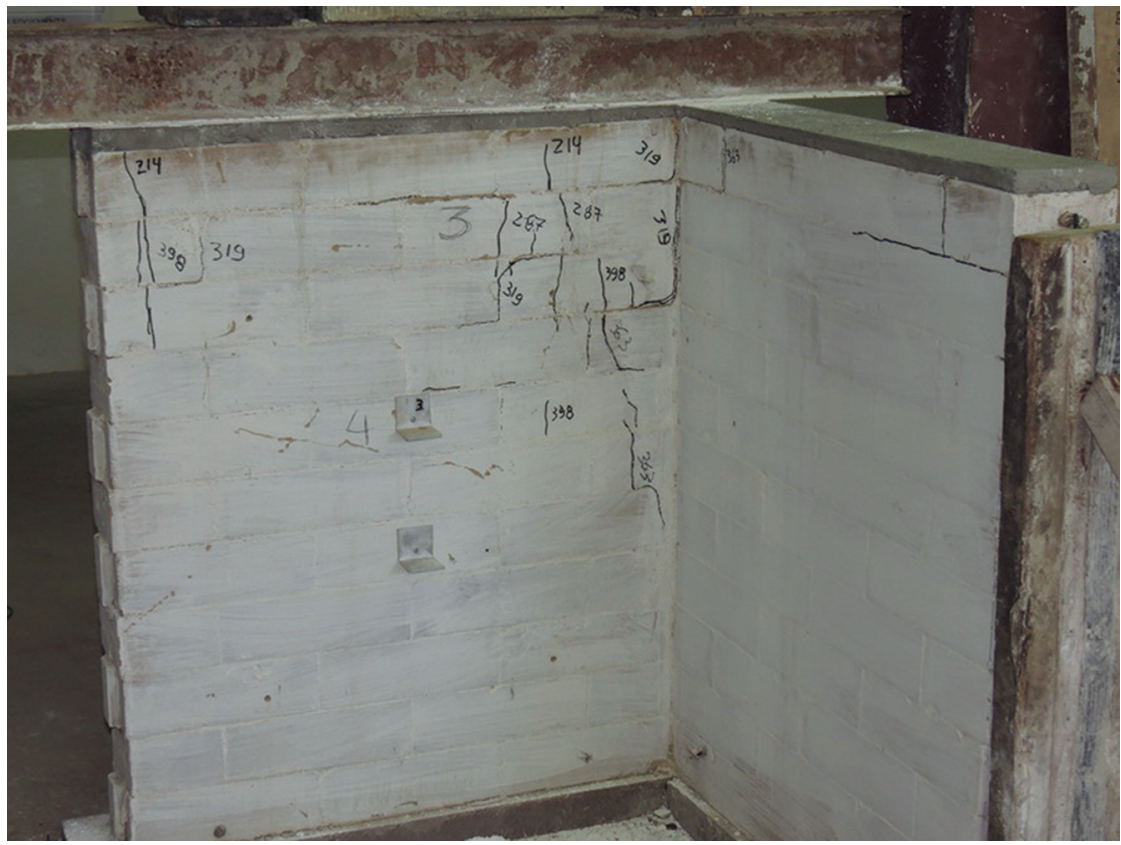

Figura 12. Estado de fissuração no lado da alvenaria submetido a carregamento.

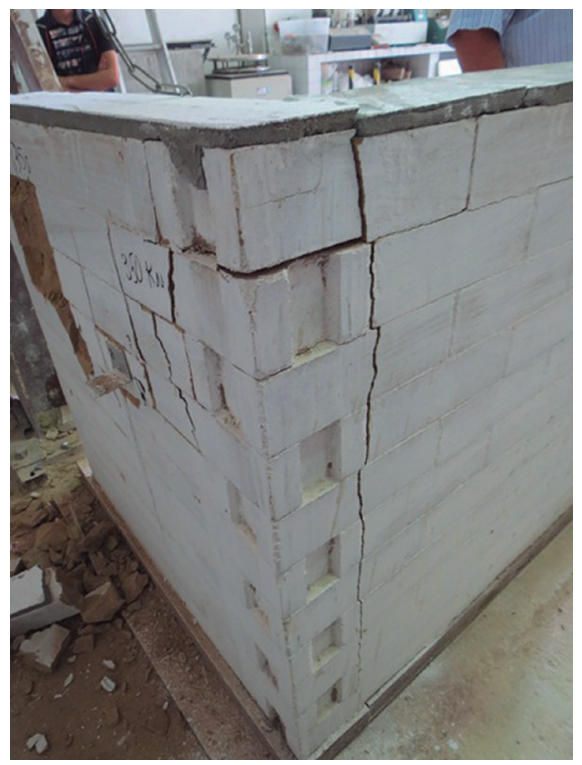

Figura 13. Transferência de carga de um lado para o outro na alvenaria em L. 


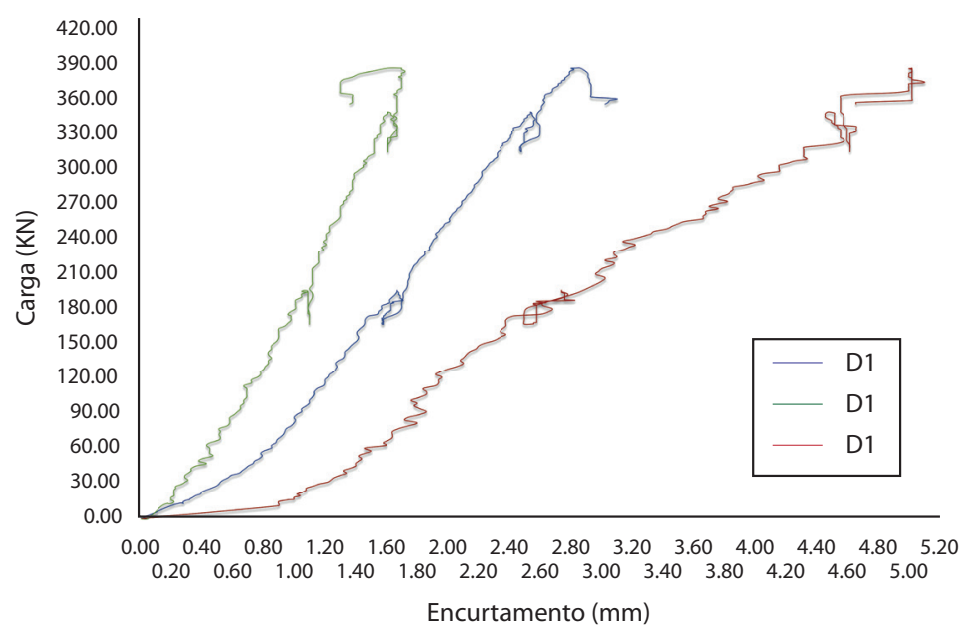

Figura 14. Curvas carga-encurtamento vertical.

Na Figura 15, tem-se um perfil da intensidade dos deslocamentos verticais. Os defletômetros D1 e D2 encontram-se situados à mesma altura, porém o D2 está mais próximo da amarração entre os planos da alvenaria. O modelo mostra nitidamente o efeito da amarração na mitigação da intensidade do encurtamento vertical. Do mesmo modo, à medida que o defletômetro se afasta da linha de carregamento, ou seja, quando situado a uma altura menor acima do piso, a magnitude do encurtamento tende a diminuir, conforme valor obtido pelo defletômetro D3.

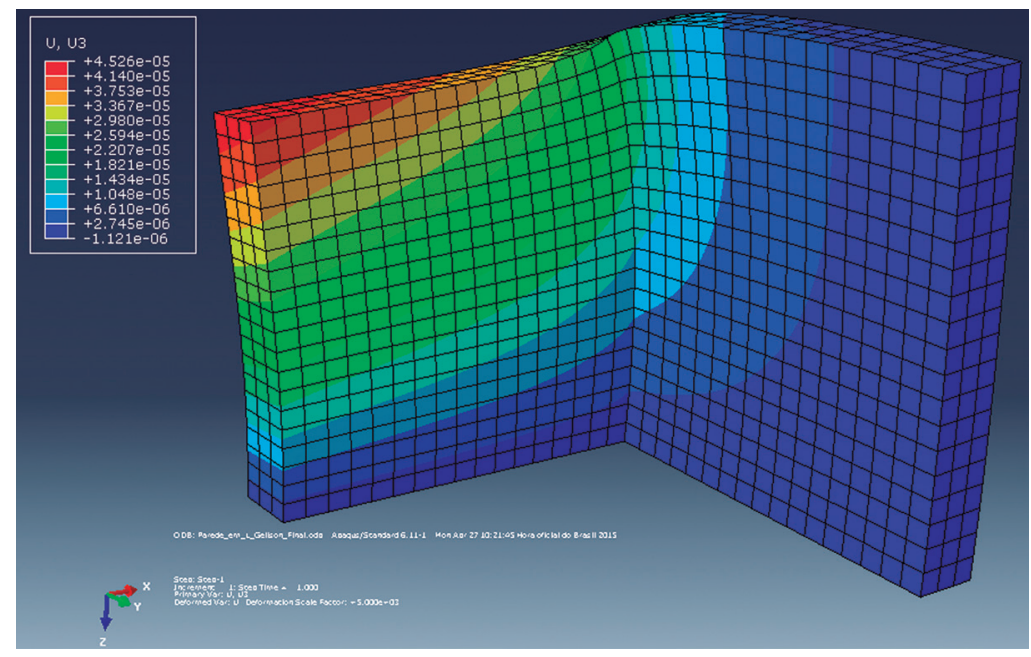

Figura 15. Campo dos deslocamentos verticais (encurtamento). 
$\mathrm{Na}$ Figura 16, apresenta-se o campo das tensóes de cisalhamento no plano S13. Observa-se que as tensões máximas de cisalhamento S13 ocorrem na região da amarração, estando seu valor na parte superior desta região , resultado que valida o modo de ruptura apresentado na Figura 13.

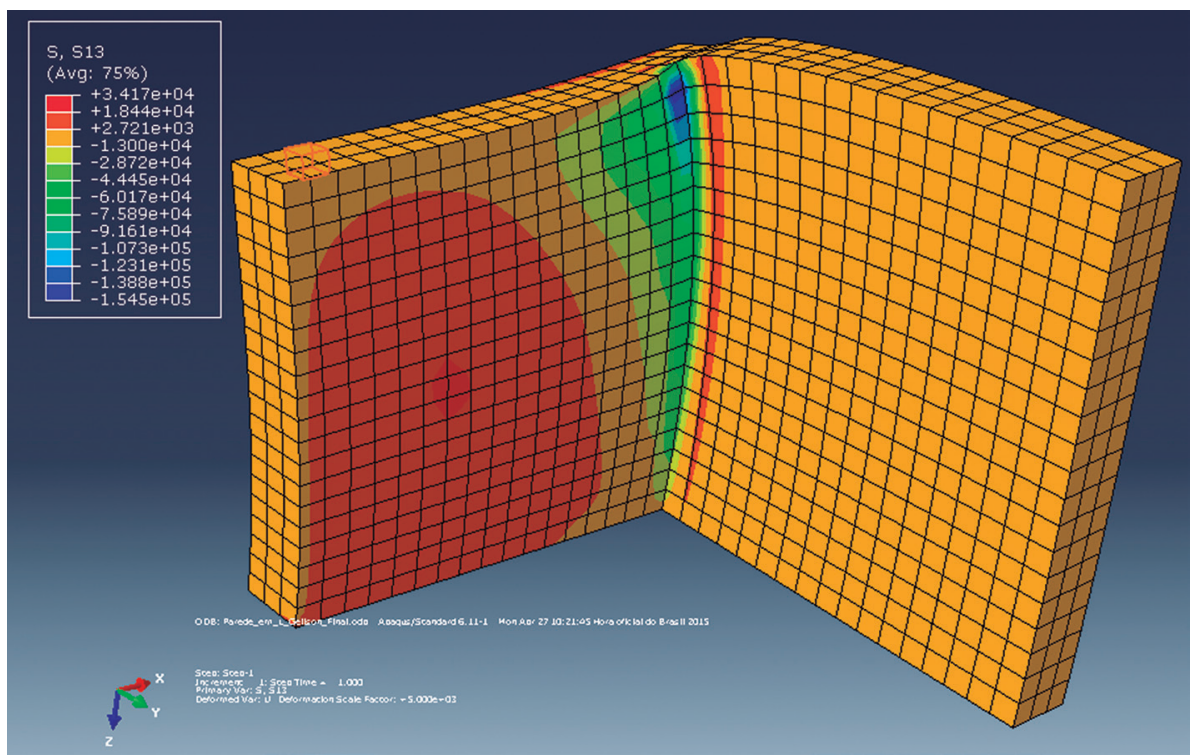

Figura 16. Campo das tensões de cisalhamento S13.

$\mathrm{Na}$ Figura 17, apresenta-se o campo das tensóes atuantes no plano vertical. Conforme esperado de acordo com a literatura, a diagonal superior da alvenaria que não recebe carregamento praticamente não é carregada à compressão, indicando um caminhamento do carregamento a $45^{\circ}$, conforme mostrado na Figura 1. 


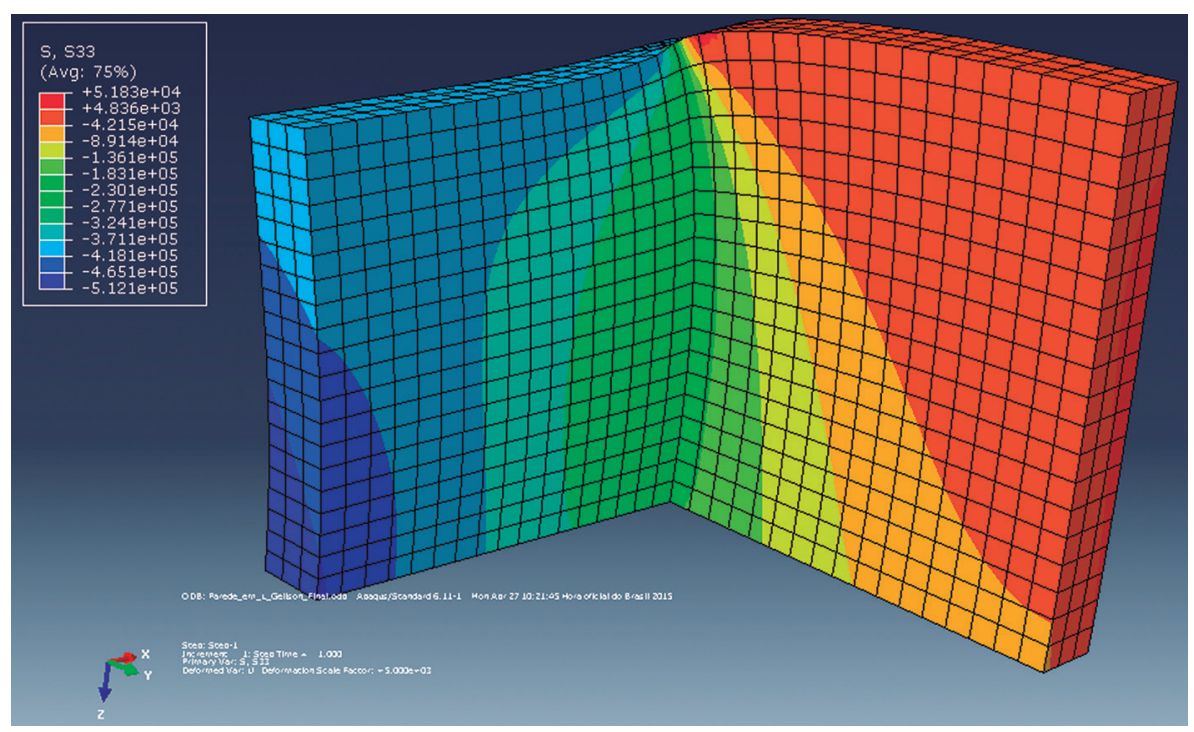

Figura 17. Distribuição das tensões normais no plano vertical.

\section{Alvenaria com Abertura, de $2,15 \mathrm{~m}$ de Altura}

$\mathrm{Na}$ alvenaria com abertura, surgiram várias fissuras, tanto na vertical como na horizontal. O rompimento mais uma vez foi causado pelo esmagamento dos blocos, da mesma forma que ocorreu na alvenaria em L, comprovando a influência do material no comportamento mecânico desse tipo de alvenaria. $\mathrm{Na}$ Figura 18, apresenta-se o gráfico carga deflexão para os três defletômetros. Conforme esperado, o D2 é o que se encurtou menos já que se encontra localizado na regiáo central, abaixo da contraverga e o D3 é o que se encurtou mais, pois recebe de forma mais imediata o efeito do carregamento distribuído. O D1, por sua vez, situado à meia altura e ao lado da abertura, apresenta ordem de grandeza intermediária de deslocamento por estar localizado abaixo da verga e acima da contraverga. Isso faz com que o carregamento transmitido a essa região já esteja diluído devido ao efeito de flexão da verga.

$\mathrm{Na}$ Figura 19, pode-se observar o efeito arco na parte superior da alvenaria, mitigando assim o efeito de flexão na verga. Apesar das condiçôes inerentes às não-linearidades geométricas e dos materiais, assim como de execução e posicionamento centrado da alvenaria sob o pórtico, os resultados encontrados foram bem simétricos e similares aos modelados por meio do Método dos Elementos Finitos, com o uso do software Abaqus. 
A primeira fissura apareceu sob um carregamento de $84 \mathrm{kN}$, na face inferior central da verga. Isso já era esperado, pelo fato de, na construção dessas vergas, ser considerado apenas 2 barras soltas de aço CA-50 para combater o efeito de flexão, sem uso de estribos. Desse modo, fica claro que esse método construtivo para as vergas não é o mais eficiente. No entanto, observou-se que, apesar da verga fissurada, a alvenaria ainda conseguiu suportar carga até aproximadamente $360 \mathrm{kN}$. Isso foi possível porque o efeito arco funcionou de modo a transmitir os esforços para a região lateral às aberturas e posteriormente para a regiáo abaixo da contraverga. Os valores de encurtamento foram obtidos até um valor de carga abaixo da ruptura, aproximadamente $230 \mathrm{kN}$, com o objetivo de não danificar os equipamentos, já que a estrutura é predominantemente constituída de materiais frágeis. Mesmo com a presença de verga, as barras de aço, por estarem soltas, não oferecem uma capacidade de tenacidade suficiente para garantir a leitura dos defletômetros até o fim.

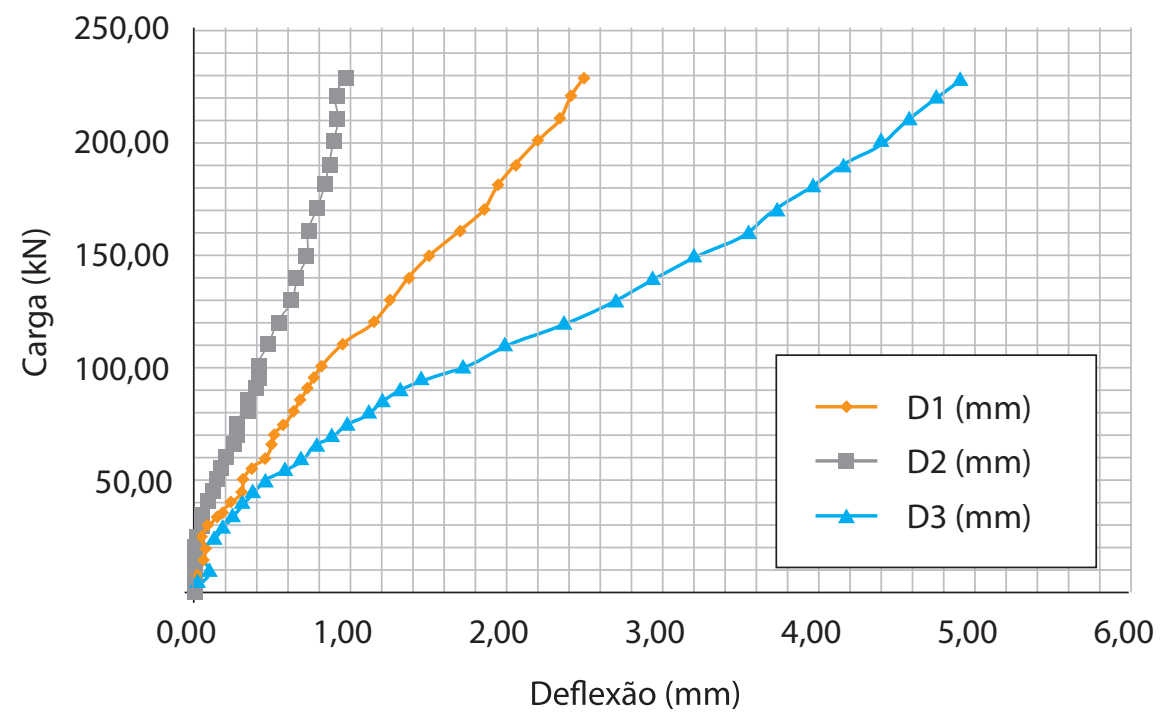

Figura 18. Distribuição das tensões normais no plano vertical. 


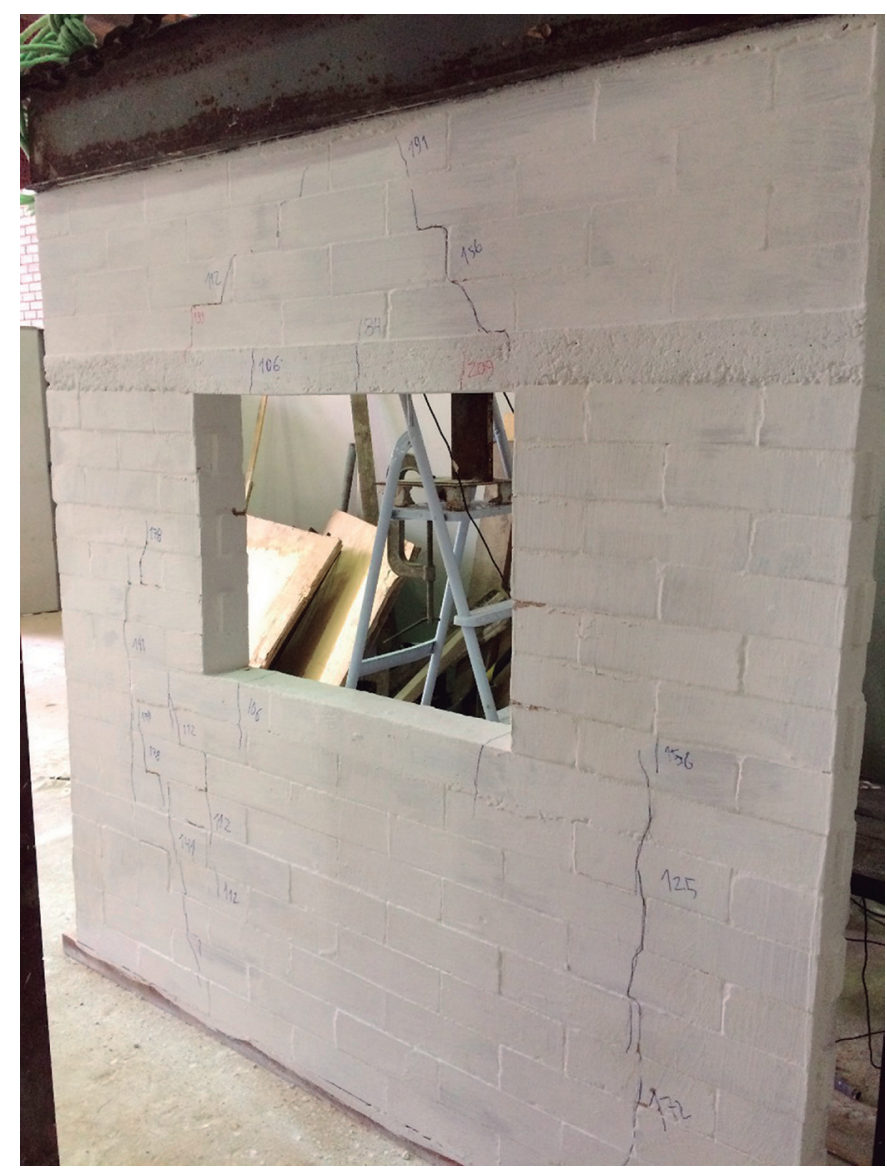

Figura 19. Distribuição das tensões normais no plano vertical.

Nas Figuras 20 e 21, são apresentadas as distribuições de tensôes nos eixos $\mathrm{X}$ e $\mathrm{Y}$, respectivamente. Na direção X, observa-se claramente o efeito da flexão na verga e do empuxo na contraverga. Além disso, de modo geral, observa-se uma distribuição uniforme de tensões de tração na alvenaria. $\mathrm{Na}$ direção $\mathrm{Y}$, entretanto, como já esperado devido ao ensaio experimental, a distribuição de tensôes não é uniforme. Observa-se, na região acima da verga, na área alaranjada sob compressão indicando a formação do arco já observado no experimento. Além disso, o modelo também mostra uma distribuição de tensôes de menor valor nas partes laterais da abertura, comprovando o ensaio experimental que apresentou, de fato, menos fissuras nessa região. 


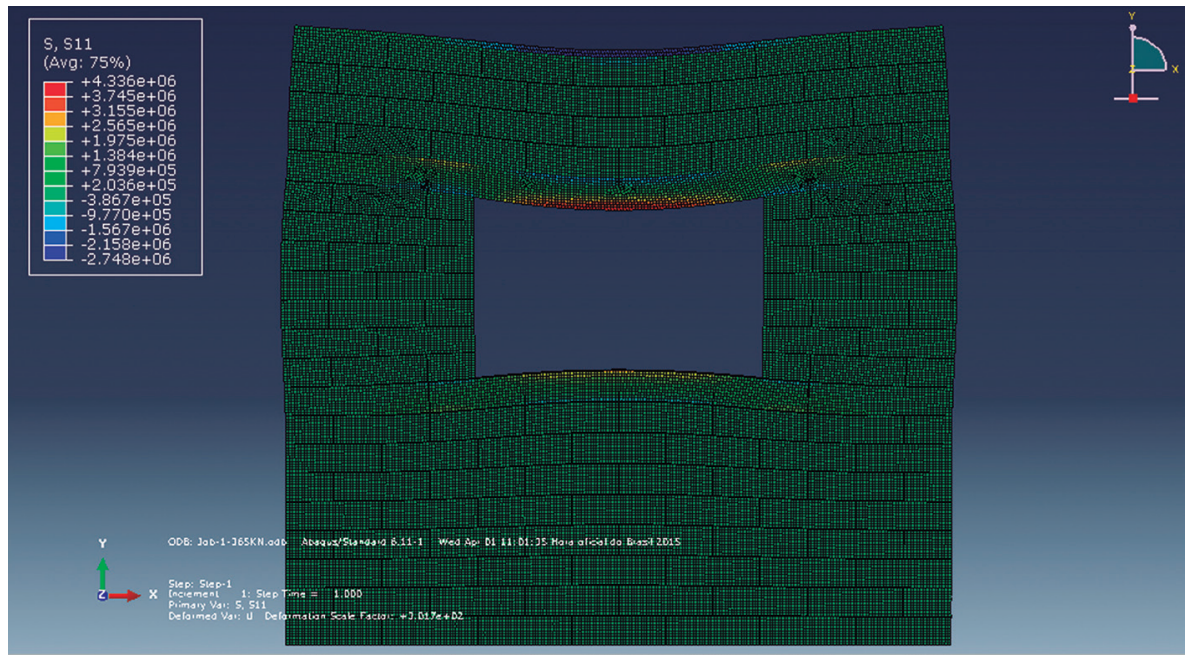

Figura 20. Distribuição de tensões na Direção $X$.

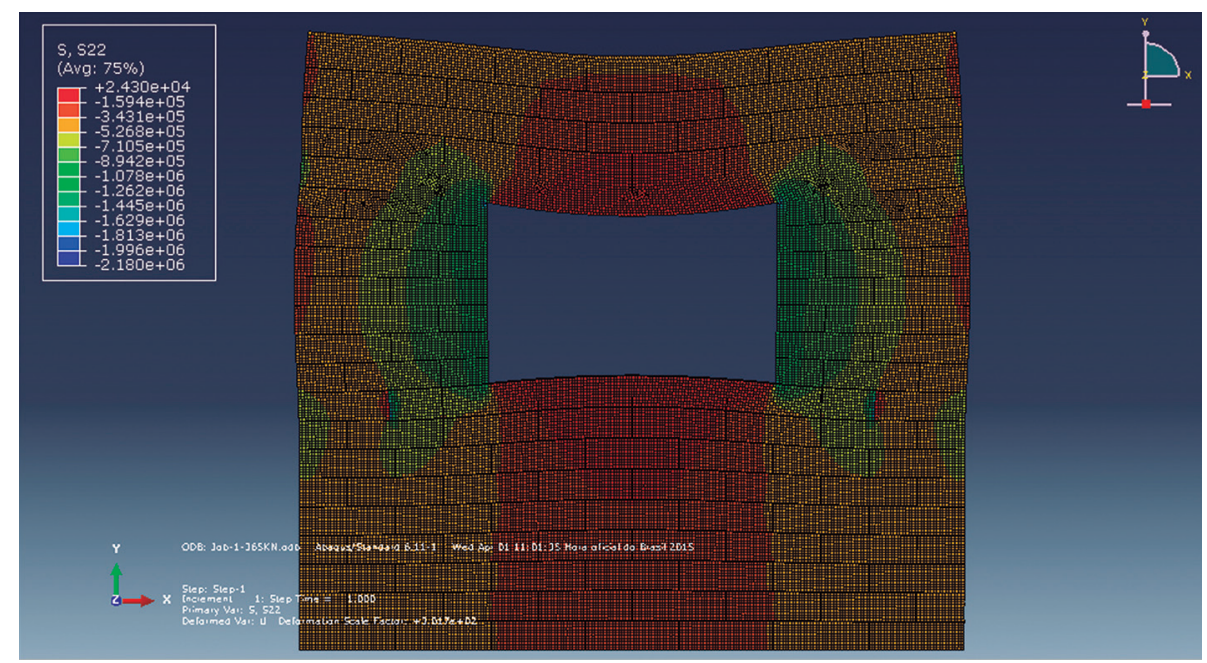

Figura 21. Distribuição de tensões na Direção $Y$.

A Figura 22 comprova que o modelo numérico foi realizado em um Estado Plano de Tensóes. 


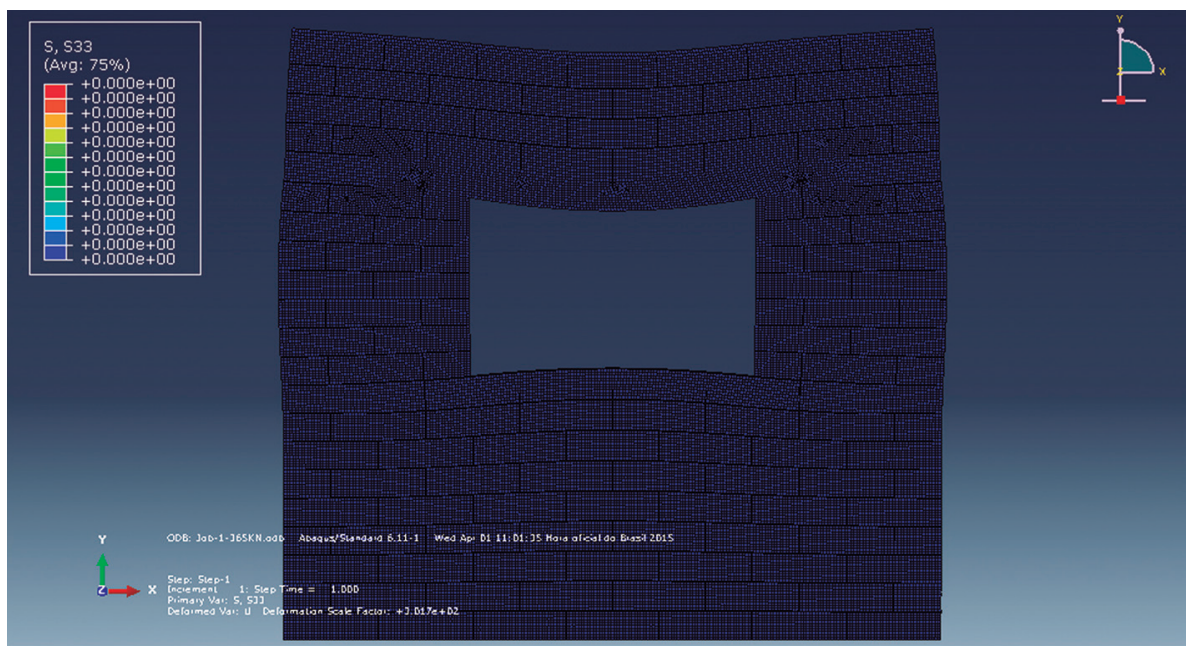

Figura 22. Distribuição de tensões na Direção Z - Estado Plano de Tensões.

\section{Considerações Finais}

Nos dois tipos geométricos de alvenaria, observou-se ruptura dos blocos, demonstrando a influência do comportamento frágil do material terra, em forma de BTC. Esse comportamento já tinha sido observado por (GONÇALVES, 2005). No que diz respsito às alvenarias de material cerâmico, também houve a transferência de esforços através da amarração, nas alvenarias em L, conforme apresentado por (RAMALHO e CORREAA, 2003). Essa transferência é garantida graças às tensôes de cisalhamento entre os planos, que garantem fisicamente a amarração. No estado limite último, observa-se que os dois planos se separam, indicando ruptura por cisalhamento, no encontro dos dois planos. Foi possível verificar, ademais, o efeito arco acima da verga, conforme já considerado pela norma NBR 15961, responsável por aliviar as tensôes de tração na região logo acima da verga. Isso é possível porque os blocos apresentam resistência à compressão suficiente para transferir os esforços de compressão em direção às laterais da alvenaria. Finalmente, é importante ressaltar a necessidade de se modelar numericamente os ensaios experimentais. Observa-se que a alvenaria apresenta náo-linearidades geométricas e de material e, ao ser colocada sob o pórtico, pode também não ficar totalmente centrada. Esses aspectos somados podem levar a resultados experimentais um pouco difíceis de serem analisados, caso sejam diferentes da hipótese esperada de comportamento. Por meio da modelagem numérica, pode-se não apenas 
validar a hipótese esperada como também os próprios resultados dos ensaios experimentais. E concluiu-se que, apesar das náo linearidades presentes no material e na estrutura estudada, problemas de execução - como prumo- , desalinhamento ou falta de retilineidade, o comportamento mecânico das alvenarias se deu de forma coerente e satisfatória, atingindo para a alvenaria em L uma carga de ruptura próxima de $500 \mathrm{kN}$ e para a alvenaria com abertura de $2,1 \mathrm{~m}$ de altura, uma carga de ruptura de $360 \mathrm{kN}$.

\section{Referências Bibliográficas}

ASSOCIAÇÃO BRASILEIRA DE NORMAS TÉCNICAS. NBR 7180 - Solo Determinação do limite de plasticidade. Rio de Janeiro, 1988.

ASSOCIAÇÃO BRASILEIRA DE NORMAS TÉCNICAS. NBR 6459 - Solo Determinação do limite de liquidez. Rio de Janeiro, 1984.

ASSOCIAÇÃO BRASILEIRA DE NORMAS TÉCNICAS. NBR 15961 - Alvenaria Estrutural - Blocos de concreto. Rio de Janeiro, 2011.

ASSOCIAÇÃO BRASILEIRA DE NORMAS TECNICAS. NBR 10836 - Bloco vazado de solo-cimento sem funçáo estrutural - Determinaçáo da resistência à compressão e da absorção de água. Rio de Janeiro, 2013.

ASSOCIAÇÃO BRASILEIRA DE NORMAS TECNICAS. NBR NM 248 - Agregado Determinação da composição granulométrica. Rio de Janeiro, 2003.

ASSOCIAÇÃO BRASILEIRA DE NORMAS TÉCNICAS. NBR NM 52 - Agregados Determinação da massa específica e massa específica aparente. Rio de Janeiro, 2009.

ASSOCIAÇÁO BRASILEIRA DE NORMAS TÉCNICAS. NBR 8492 - Tijolo Maciço de Solo-cimento - Determinação da resistência a compressão e da absorçáo d'agua. Rio de Janeiro, 2012.

BARBOSA, N. P., GHAVAMI, K., Terra Crua para Edificaçóes. Materiais de Construção Civil e princípios da Engenharia de Materiais. 1. ed. São Paulo. IBRACON, 2007, v. 2, p. 1505-1538.

BAUER, R. J. F. Patologias em alvenaria estrutural de blocos de vazados de concreto. Revista Prima - Caderno Técnico de Alvenaria Estrutural, São Paulo. 13. ed., 2007.

BROWN, J.; EVANS, M.; MORROW, C. Model Block Press, Mechanical Engineering Department. California Polytechnic State University - San Luis Obispo, 2014.

GONÇALVES, J. S. Contribuiçāo para a normalizaçâo da alvenaria estrutural com o uso de tijolos de terra crua para construçóes urbanas. 2005. Dissertação (Mestrado em Engenharia Urbana) - Universidade Federal da Paraíba, Joáo Pessoa.

GUETTALA, A.; ABIBSI, A;. HOUARI, H. Durability study of stabilized earth concrete under both laboratory and climatic conditions exposure. Construction and Building Materials, v. 20, p. 119-127, 2006. 
HEATHCOTE, K. A. Durability of earthwall buildings. Building Mater, v. 9, n. 3, p. 185-189, 1995.

MEDEIROS, J. S. Alvenaria estrutural não armada de blocos de concreto: produção de componentes e parâmetros de projeto. 1993. Dissertação (Mestrado em Engenharia Civil) Escola Politécnica. Universidade de São Paulo, São Paulo.

PAGE, A. W. Finite element model for masonry. Journal of Structural Division, ASCE, v. 104, n. ST8, Aug. 1978.

PINTO, T. P. Evolução das pesquisas de laboratório sobre solo-cimento. São Paulo: ABCP, 22 p. 1980.

PORTLAND CEMENT ASSOCIATION (PCA). Soil-cement construction handbook. Illinois, 42 p. 1969.

PROMPT, C. H.; BORELLA, L. L. Experiências em construção com terra no segmento da agricultura familiar. Terra Brasil. III Congresso de Arquitetura e Construção com terra no Brasil, Campo Grande - MS, 2010.

RAMAlHO, M. A.; CORREAA, M. R. S. Projeto de Edifícios de Alvenaria Estrutural. Pini. 2003, São Paulo.

ROMAN, H. R. et al. Análise de Alvenaria Estrutural. Santa Catarina: Universidade Corporativa Caixa, 2007, 168 p.

SAMPAIO, M. B. Fissuras em Edifícios Residenciais em Alvenaria Estrutural. 2010. 122 f. Dissertação (Mestrado em Engenaharia de Estruturas) - Escola de Engenharia de São Carlos, Universidade de Sáo Paulo, São Carlos.

SANTOS, C. A. Construção com Terra no Brasil: Panorama, Normatização e Prototipagem com Terra Ensacada, 2015. Dissertação (Mestrado) - Programa de Pós-graduação em Arquitetura e Urbanismo da Universidade Federal de Santa Catarina, Florianópolis.

TAUIL, C. A.; MARTINS NESE, F. J. Alvenaria Estrutural. São Paulo: Pini, 2010.

VENDRAME, G. Alvenaria Estrutural: fundamentos de cálculo para blocos vazados de concreto. Itatiba: Universidade São Francisco, 2008. 
